Article

\title{
Impact of Obstructive Sleep Apnea on In-Hospital Outcomes of Patients with Non-ST Elevation Myocardial Infarction
}

\author{
Sakiru Oyetunji Isa ${ }^{1, * \mathbb{D}}$, Oluwole Adegbala ${ }^{2}$, Olajide Buhari ${ }^{3}$, Mahin Khan ${ }^{1}$, Orimisan Adekolujo ${ }^{1}$, \\ Oyebimpe Adekolujo ${ }^{1}$, Ahmad Munir ${ }^{1}$ and Mustafa Hassan ${ }^{1}$ \\ 1 Department of Medicine, Mclaren Flint, Flint, MI 48532, USA; Mahin.khan@mclaren.org (M.K.); \\ orimisanadekolujo@yahoo.com (O.A.); oyebimpe.adekolujo@mclaren.org (O.A.); amunirmd@aol.com (A.M.); \\ mhassan@hrcmichigan.com (M.H.) \\ 2 Division of Cardiology, Detroit Medical Center, Detroit, MI 48201, USA; Oluwole.adegbala@yahoo.com \\ 3 Department of Medicine, Jacobi Medical Center, New York, NY 10461, USA; olajidebuhari@gmail.com \\ * Correspondence: sakiru.isa@mclaren.org
}

Citation: Isa, S.O.; Adegbala, O.; Buhari, O.; Khan, M.; Adekolujo, O.; Adekolujo, O.; Munir, A.; Hassan, M. Impact of Obstructive Sleep Apnea on In-Hospital Outcomes of Patients with Non-ST Elevation Myocardial Infarction. Hearts 2021, 2, 119-126. https://doi.org/10.3390/hearts2010009

Received: 2 January 2021

Accepted: 5 February 2021

Published: 7 February 2021

Publisher's Note: MDPI stays neutral with regard to jurisdictional claims in published maps and institutional affiliations.

Copyright: (c) 2021 by the authors. Licensee MDPI, Basel, Switzerland. This article is an open access article distributed under the terms and conditions of the Creative Commons Attribution (CC BY) license (https:// creativecommons.org/licenses/by/ $4.0 /)$.

\begin{abstract}
Background: Obstructive sleep apnea (OSA) is one of the most common breathing disorders. There are uncertainties about its impact on the in-hospital outcomes of patients who suffer acute coronary syndromes. We studied the largest publicly available all-payer inpatient healthcare database in the United States (National Inpatient Sample) to determine the effects of obstructive sleep apnea on the in-hospital outcomes of patients admitted with non-ST elevation myocardial infarction (NSTEMI). Methods: All adult patients (age $\geq 18$ ) admitted primarily for NSTEMI between September 2010 and September 2015 were identified in the National Inpatient Sample. They were then categorized into those with OSA and those without OSA. The main outcome was in-hospital mortality. Propensity scoring and logistic regression models were created to determine the outcomes. Results: There were 1,984,432 patients with NSTEMI (weighted estimates), 123,551 (6.23\%) of who had diagnosed OSA while 1,860,881 (93.77\%) did not. In-hospital mortality was significantly lower in the OSA group [2.61\% vs. $3.53 \%$, adjusted odd ratio (aOR) 0.73 and confidence interval (CI) (0.66-0.81)]. Patients with OSA were also less likely to require coronary artery bypass surgery: $13.85 \%$ and $12.77 \%$ ( $p$-value 0.0003). The patients with OSA had higher mean hospital costs compared to the patients who did not have OSA: $\$ 17,326$ vs. $\$ 16,984$, adjusted mean ratio (aMR) 1.02; CI (1.01-1.02). Conclusion: In-hospital mortality was lower in NSTEMI patients with diagnosed OSA compared to patients without diagnosed OSA. This appears to contrast with the widely recognized adverse effects of OSA on the cardiovascular system.
\end{abstract}

Keywords: ACS; in-hospital; mortality; NSTEMI; OSA

\section{Introduction}

Obstructive sleep apnea (OSA) is a sleep related disorder characterized by intermittent sleep disruption, repeated apnea and nocturnal hypoxemia [1]. It is one of the most common breathing diseases in the United States. It is estimated to affect about $5 \%$ of adults in North America [2,3]. Over the years, OSA has been established to have strong associations with cardiovascular co-morbidities and adverse long-term cardiovascular outcomes [2,4]. These associations persist even after correcting for comorbidities and risk factors such as sex, obesity, and age [5]. There are debates about the impact of obstructive sleep apnea on the in-hospital outcomes of patients who suffer acute coronary syndromes [6]. In a recent study, there was improved in-hospital outcomes in patients with OSA and ST elevation myocardial infarction (STEMI) [7]. Nevertheless, evidence for in-hospital outcomes in patients with OSA and NSTEMI is limited in the literature. We studied the National Inpatient Sample (NIS) to determine the relationship between obstructive sleep apnea and in-hospital outcomes in patients with NSTEMI. 


\section{Methods}

\subsection{Data Source}

The study was exempted from full review by the institutional review board at Mclaren Flint. It was a retrospective cohort study in which the authors interrogated the NIS from September 2010 to September 2015. The database, sponsored by the Agency for Healthcare Research and Quality (AHRQ) includes primary diagnoses, comorbidities, and complications as well as patient characteristics of hospital admissions. Diagnoses in this database are identified with their international classification of diseases (ICD) codes.

The NIS provides national estimates of hospital stays in the United States. It is the largest publicly available all-payer inpatient healthcare database in the country [8]. Until 2011, the NIS included $100 \%$ of discharges from a $20 \%$ random sample of all hospitals stratified by location, hospital region, teaching status and bed size.

In 2012, the NIS was redesigned to improve the precision of national estimates, and now it consists of a $20 \%$ random sample of discharges selected from $100 \%$ of the participating hospitals. The Agency for Healthcare Research and Quality (AHRQ) provide trend weights to use with the database [8]. Results from the NIS have been shown to correlate well with other hospitalization and discharge databases in the United States.

\subsection{Patients' Characteristics}

The database was studied to identify all patients (age $\geq 18$ ) admitted primarily for NSTEMI between September 2010 and September 2015. These patients were then stratified into those with OSA and those without OSA. ICD-9 codes were used to identify these cases. ICD-9 codes for NSTEMI and OSA are 410.71 and 327.23, respectively. We excluded those discharged alive on the same day as they are unlikely to truly represent the cohort of interest of this study. Patients who were transferred to other acute care facilities were also excluded.

Data were obtained on patient characteristics and hospital-level characteristics. These included age, sex, race, health insurance status, income level, and co-morbidities. We then compared clinical outcomes among patients with OSA and those without OSA.

\subsection{Clinical Outcomes}

The main outcome was in-hospital mortality. Secondary outcomes included type of revascularization, cardiac arrest, acute kidney injury, ischemic stroke, hospital cost, and length of hospital stay. Demographic and co-morbid factors were identified as covariates. Elixhauser Co-morbidities Index was computed to summarize these comorbid variables into numbers.

Assessment of healthcare resources was performed by comparing non-routine home discharge rate, cost, and length of stay. Hospital cost information was obtained from the hospital accounting reports collected by the Centers for Medicare \& Medicaid Services. To account for the effect of inflation on hospital charges, we used data from the Bureau of Labor Statistic's medical care component of the Consumer Price Index (CPI) and presented the data in 2019 US dollars.

The national estimates were the hospital-level trend/discharge weights included in the NIS by AHRQ.

\subsection{Statistical Analysis}

Data were analyzed with Statistical Analysis System (SAS V.9.4, SAS Institute Inc, Cary, NC, USA), accounting for the stratified sampling design with appropriate keywords as recommended by HCUP-NIS [9]. The adjusted odds ratio (AOR) was reported for logistic models and adjusted mean ratio (AMR) for numeric variables-cost and length of stay. Absolute standardized differences (ASD) were used to compare the baseline characteristics. ASD (calculated as the differences in means or proportions divided by a pooled estimated of the SD) is not as sensitive to sample size compared with traditional significance testing and 
it is useful in identifying clinically meaningful differences. An ASD of $>0.1$ is considered clinically meaningful.

To account for potential confounding, propensity score method with standardized morbidity ratio (SMR) weighting was employed. The propensity of each patient with OSA versus no OSA was estimated using the variables in Table 1 . An interaction term between age categories was included in the model. The missing data included hospital region $(2.40 \%)$, race $(7.59 \%)$, primary expected payer $(0.14 \%)$, household income status $(2.07 \%)$, hospital bed size $(0.44 \%)$, and hospital teaching status $(0.44 \%)$. To enable the inclusion of the missing variables in the PS estimated, these categorical variables with $<2 \%$ missing data were replaced with the dominant category and, if a variable had $>2 \%$ missing values (race, house income, and hospital region), the missing values were treated as a separate category. This method was used in prior studies.

Table 1. Propensity score-standardized morbidity ratio (SMR) weighted baseline characteristics of patients with NSTEMI by OSA status.

\begin{tabular}{|c|c|c|c|}
\hline \multirow{2}{*}{ Items } & \multicolumn{2}{|c|}{ OSA Status } & \multirow{2}{*}{$¥ \mathrm{SD}$} \\
\hline & Non-OSA & OSA & \\
\hline Age-year, mean (SD) & $64.78(3.14)$ & $64.78(12.05)$ & 0.0005 \\
\hline Female, $\%$ & 31.66 & 31.66 & 0.0000 \\
\hline Race/Ethnicity, \% & & & 0.0000 \\
\hline -White & 71.26 & 71.32 & \\
\hline -Black & 11.50 & 11.55 & \\
\hline -Hispanic & 5.20 & 5.21 & \\
\hline -Asia & 1.12 & 1.13 & \\
\hline -Missing & 8.41 & 8.28 & \\
\hline Dyslipidemia & 72.72 & 72.63 & 0.0019 \\
\hline Prior myocardial infarction & 15.97 & 15.94 & 0.0009 \\
\hline Prior percutaneous coronary intervention & 19.99 & 20.03 & 0.0009 \\
\hline Prior coronary artery bypass grafting & 11.25 & 11.33 & 0.0023 \\
\hline Prior pacemaker & 3.59 & 3.65 & 0.0034 \\
\hline Atrial fibrillation & 21.19 & 21.45 & 0.0063 \\
\hline Chronic obstructive pulmonary disease & 33.40 & 33.84 & 0.0093 \\
\hline Prior cerebrovascular disease & 8.08 & 8.13 & 0.0019 \\
\hline Hypertension & 81.28 & 81.35 & 0.0018 \\
\hline Peripheral vascular diseases & 15.30 & 15.36 & 0.0017 \\
\hline Hypothyroidism & 13.50 & 13.56 & 0.0017 \\
\hline Diabetes mellitus & 57.26 & 57.34 & 0.0017 \\
\hline Obesity & 47.79 & 48.13 & 0.0069 \\
\hline Deficiency Anemia & 20.75 & 20.78 & 0.0008 \\
\hline Congestive heart failure & 41.27 & 41.69 & 0.0087 \\
\hline Renal failure & 29.92 & 30.02 & 0.0022 \\
\hline Liver disease & 2.02 & 2.04 & 0.0013 \\
\hline On maintenance dialysis & 4.16 & 4.16 & 0.0001 \\
\hline Smoking & 42.26 & 42.36 & 0.0020 \\
\hline Weekend admission, $\%$ & 26.30 & 26.27 & 0.0007 \\
\hline Elixhauser score \% & & & 0.0000 \\
\hline-1 & 9.87 & 9.84 & \\
\hline$-2-3$ & 39.91 & 39.55 & \\
\hline$-\geq 4$ & 50.23 & 50.61 & \\
\hline Hospital bed size, $\%$ & & & 0.0000 \\
\hline -Small & 10.25 & 10.20 & \\
\hline -Medium & 25.31 & 25.23 & \\
\hline -Large & 64.43 & 64.57 & \\
\hline
\end{tabular}


Table 1. Cont.

\begin{tabular}{|c|c|c|c|}
\hline \multirow{2}{*}{ Items } & \multicolumn{2}{|c|}{ OSA Status } & \multirow{2}{*}{${ }^{¥} \mathrm{SD}$} \\
\hline & Non-OSA & OSA & \\
\hline Expected primary payer, $\%$ & & & 0.0000 \\
\hline -Medicare & 58.12 & 58.16 & \\
\hline -Medicaid & 7.42 & 7.36 & \\
\hline -Private & 27.76 & 27.71 & \\
\hline -Self pay & 3.63 & 3.66 & \\
\hline -Others & 3.07 & 3.10 & \\
\hline Median household income in quartile, $\%$ & & & 0.0000 \\
\hline$-1 s t$ & 29.01 & 29.06 & \\
\hline-2 nd & 27.23 & 27.08 & \\
\hline$-3 \mathrm{rd}$ & 24.14 & 24.17 & \\
\hline-4 th & 17.85 & 17.93 & \\
\hline -Missing & 1.76 & 1.76 & \\
\hline Hospital Region, \% & & & 0.0000 \\
\hline -Northeast & 14.97 & 14.96 & \\
\hline -Midwest & 27.87 & 27.97 & \\
\hline -South & 38.92 & 38.81 & \\
\hline -West & 16.19 & 16.20 & \\
\hline -Missing & 2.05 & 2.05 & \\
\hline Hospital Teaching status & & & 0.0217 \\
\hline -Rural & 7.23 & 7.29 & \\
\hline -Urban, non-teaching & 32.49 & 32.50 & \\
\hline -Urban, Teaching & 60.28 & 60.21 & \\
\hline
\end{tabular}

¥ ASD Indicates absolute standardized differences, calculated as differences in means or proportions divided by a pooled estimate of the SD.

A standardized morbidity ratio (SMR) weight was calculated for each patient, and patients who had OSA were assigned a weight of 1 , while those without OSA were weighed using PS/(1-PS). SMR weights standardize the distribution of measured demographic, hospital, and hospital characteristics in OSA patients to the distribution of those without OSA [10]. Trimming at the $1 \%$ and $99 \%$ cut points was performed to remove nonoverlapping regions. This is done because patients in the nonoverlapping regions are not at risk for being in the other group. Once the weights were applied, the balance was assessed by examining standardized differences between the two groups.

Standardized models were used to compare the clinical outcomes of patients with OSA and patients without diagnosed OSA. Binary outcomes were modeled with SMRweighted binomial logistic regressions. Discrete numeric variables with an over-dispersion were-length of stay and hospitalization cost. They were first log-transformed by a natural logarithmic scale and back-transformed to obtain the expected days and cost, respectively.

Finally, we included interaction terms in the logistic regression model to determine whether the relations between mortality and OSA status varied by age categories, type of revascularization and gender.

\section{Results}

In the study, there was a total of 1,984,432 patients with non-ST elevation myocardial infarction (weighted estimates), 123,551(6.23\%) of whom had OSA while 1,860,881 (93.77\%) did not. Table 1 shows the baseline characteristics. Patients with OSA were younger with average age of $64.59 \pm 11.91$ compared to $69.28 \pm 14.13(\mathrm{ASD}=0.36$ ). The OSA group were also less likely to be females ( $30.09 \%$ vs. $42.74 \%$, ASD 0.26 ). The OSA group had a higher proportion of white (71.74) and black people (11.41\%) compared to the non-OSA group with $68.83 \%$ white people and $11.17 \%$ black people, respectively. 
Co-existing conditions such as dyslipidemia, chronic obstructive pulmonary disease, prior percutaneous coronary intervention, hypertension, diabetes mellitus, chronic renal failure, congestive heart failure, and obesity were significantly more prevalent in patients who had OSA (all ASD > 0.1). There were no significant differences between the two groups regarding smoking status, maintenance dialysis, chronic liver disease, peripheral vascular disease, prior myocardial infarction, prior coronary artery bypass grafting statuses, hospital status, hospital bed size, and household income (all ASD $<0.1$ ).

Table 2 shows the primary and secondary outcomes. The primary outcome of interest, in-hospital mortality was significantly lower in the OSA group [2.61\% vs. 3.53\%, adjusted odd ratio (aOR) 0.73 , CI: 0.66-0.81]. Coronary artery bypass graft (CABG) was utilized less often in OSA vs. non-OSA group (12.77 vs. $13.85, p$-value $=0.0003)$. However, there was no statistical difference between the two groups with regards to percutaneous coronary interventions (PCI). Ischemic stroke was less frequent in the OSA group $(0.86 \%)$ than the non-OSA group $(1.21 \%)$ ( $p$-value $=0.0002)$. The patients with OSA stayed longer in the hospital compared to the patients who did not have OSA (4.10 days vs. 3.96 days, $p$-value $<0.0001)$ and had higher hospital cost $[\$ 17,326$ vs. $\$ 16,984$, [adjusted mean ratio (aMR) 1.02; CI (1.01-1.02) $p$-value < 0.0001].

Table 2. Multivariate adjusted model predicting different clinical outcomes by patients with OSA in reference to patients with non-OSA.

\begin{tabular}{ccccc}
\hline & OSA & Non-OSA & aOR/aMR (95\% CI) & $p$-Value \\
\hline In-patient mortality & 2.61 & 3.53 & $0.73(0.66-0.81)$ & $<0.0001$ \\
Medical therapy, \% & 47.40 & 45.69 & $1.08(1.04-1.12)$ & $<0.0001$ \\
PCI, \% & 40.29 & 40.97 & $0.97(0.93-1.01)$ & 0.0927 \\
CABG, \% & 12.77 & 13.85 & $0.91(0.86-0.98)$ & 0.0003 \\
Cardiac arrest, \% & 1.90 & 2.12 & $0.89(0.78-1.02)$ & 0.0910 \\
Ischemic stroke, \% & 0.86 & 1.21 & $0.71(0.59-0.85)$ & 0.0002 \\
Acute kidney Injury, \% & 20.61 & 20.28 & $1.02(0.98-1.07)$ & 0.3392 \\
Cost-mean, \$ & 17,326 & 16,984 & $1.02(1.01-1.02)$ & $<0.0001$ \\
$*$ Length of stay-mean, days & 4.10 & 3.96 & $1.03(1.02-0.03)$ & $<0.0001$ \\
\hline
\end{tabular}

$\overline{\mathrm{aOR}}$, adjusted odd ratio; aMR, adjusted mean ratio. ${ }^{*}$ Length of stay among those that survived till hospital discharge.

The subgroup analysis revealed lower mortality in patients with OSA across the prespecified subgroups except in patients who were less than 55 years (Table 3 ).

Table 3. Subgroup analysis: mortality by age, gender and revascularization strategy.

\begin{tabular}{ccccc}
\hline \multicolumn{5}{c}{ Age } \\
\hline Age category & $<55$ years & $55-65$ years & $>65$ years & $\mathrm{P}^{*}$ \\
\hline In-patient mortality & $0.93(0.65-1.33)$ & $0.68(0.53-0.85)$ & $0.73(0.64-0.82)$ & 0.33 \\
\hline \multicolumn{5}{c}{ Gender } \\
\hline Gender category & Female & Male \\
\hline In-patient mortality & $0.81(0.67-0.97)$ & $0.70(0.62-0.80)$ \\
\hline \multicolumn{5}{c}{ Revascularization Strategy } \\
\hline Treatment category & $\begin{array}{l}\text { Medical } \\
\text { therapy }\end{array}$ & PCI & CABG \\
\hline In-patient mortality & $0.70(0.62-0.80)$ & $0.84(0.65-1.09)$ & $0.66(0.46,0.96)$ & 0.41 \\
\hline P* for p interaction. & &
\end{tabular}

\section{Discussion}

In this study, we found that OSA patients admitted with NSTEMI were younger and less likely to be females when compared with NSTEMI patients who did not have OSA. Mortality was lower in OSA patients admitted for NSTEMI. The proportions of patients 
who had PCI were similar across both groups while less of the OSA cohorts had bypass surgery for NSTEMI.

Our study agrees with most of the already published works that OSA affects more men than women [11]. Some studies have claimed that OSA is more common in young adults while others suggested rising prevalence with advancing age $[12,13]$. We also found that relatively more of the patients with OSA were Caucasians and African Americans while relatively fewer of them were Hispanics. Traditionally, African Americans and Caucasians have been held to have higher prevalence of OSA compared to Hispanics, but newer studies are suggesting that prevalence is similar across ethnic and racial divides [14,15].

Along with craniofacial anomalies, obesity is the most strongly established risk factor for OSA [16]. The findings from our study are consistent with this. More than half of the patients in the OSA group were obese compared with just over thirteen percent in the non-OSA group. We also found dyslipidemia and diabetes mellitus to be more common in NSTEMI patients with OSA than those who did not have OSA. While a causal relationship is not yet established, previous studies have demonstrated independent association between dyslipidemia and obstructive sleep disorder [17]. The details of the relationship between OSA and diabetes mellitus is not known for certain but some studies have suggested a twoway relationship with intermittent nocturnal hypoxemia contributing to impaired glucose metabolism and diabetic neuropathy playing some roles in the disordered breathing of OSA [18].

The primary outcome of in-hospital mortality was significantly lower in patients with OSA at $2.61 \%$ compared to $3.53 \%$ in patients without OSA. This was consistent across the age groups, treatment modalities, and gender categories. Most of the available studies agree that OSA worsens long-term (six months to one year) cardiovascular outcomes [19]. This is especially true with increasing severity of OSA [20]. Some researchers have suggested prolonged ischemia and dysfunctional ventricular remodeling as the main drivers of the adverse outcomes following ACS in patients with OSA [21]. Overall, there are still uncertainties about the effect of OSA on the in-hospital and short-term outcomes of patients with ACS. Many of the available studies suggest that OSA has no effect on ACS outcomes in the hospitalization period [22]. Few studies have demonstrated significantly worsened in-hospital outcomes in non-ST elevation acute coronary syndrome patients with OSA [6]. An earlier study using the NIS database found lower in-hospital mortality in patients with STEMI who also had OSA [7]. This is consistent with our findings. This may be related to repeated hypoxia in OSA patients leading to "ischemic preconditioning" which have been demonstrated in some studies to reduce infarct sizes and improve cardiovascular outcomes following ACS [23]. On the other hand, Joyeux-Faure et al. demonstrated larger infarct sizes in animal models exposed to chronic intermittent hypoxia [24] Early growth response-1 (EGR-1) has been identified as the driving force for myocardial protection in ischemic preconditioning [25]. Widespread potassium-ATP channel activation has also been linked to this phenomenon [26].

More of the patients with OSA were treated medically while more of the patients without OSA had coronary artery bypass graft. The proportions of patients treated with PCI were comparable across both groups. An earlier study using the NIS database had suggested that more OSA patients had CABG following STEMI compared to their non-OSA counterparts [8]. This may be a pointer to lower severity of NSTEMI in patients with OSA. The study also found ischemic stroke in fewer OSA patients admitted for NSTEMI. This contrasts with previous studies that have established obstructive sleep apnea as a risk factor for ischemic stroke [27].

NSTEMI patients with OSA were found to spend more days in the hospital. They were also found to have higher hospital bills. An earlier study also showed similar findings in STEMI patient with OSA [7]. This may indicate more aggressive management of the OSA patients with myocardial infarction. This may partly explain the lower mortality in the OSA group. Since patients were not generally screened for OSA at presentation, it is possible that a significant proportion of patients in the non-OSA group actually had unrecognized 
OSA. A higher proportion of patients in the OSA were obese. "Obesity paradox" may also be a reason for improved outcomes in patients with OSA compared to those who do not have OSA. Obesity paradox is the phenomenon whereby people with obesity experience better cardiovascular outcomes compared to their non-obese counterparts [28]. However, recent studies are casting doubt on the true existence of the obesity paradox [29]. Overall, more work needs to be done in this area to understand the reasons for lower mortality in OSA patients with NSTEMI.

\section{Limitations}

Limitations of this study include its non-randomized nature. Although we conducted propensity matching and subgroup analysis, it is difficult to know the extent to which confounders affected the findings. The severity of NSTEMI and OSA as well as infarct sizes were not specified in the database. Thus, it was impossible to control for the severity of either condition in estimating the outcomes of interest. The diagnostic modalities for OSA were not specified in the database, but the diagnostic accuracies for NSTEMI in both groups were likely to be similar, as utilization of PCI was similar in both groups. The details of treatment for OSA and comorbidities were not available in the database.

\section{Conclusions}

In the present study, there was lower in-hospital mortality in NSTEMI patients with diagnosed OSA compared to patients without OSA. Follow up studies will improve our understanding of the relationship between OSA and in-hospital outcomes in patients with NSTEMI.

Author Contributions: Conceptualization: S.O.I. and O.B.; Methodology; S.O.I., O.A. (Orimisan Adekolujo) and M.K.; SOFTWARE: S.O.I., O.A. (Oluwole Adegbala), A.M., M.H. and O.B.; Validation, A.M., O.A. (Oluwole Adegbala) and M.H.; Formal analysis, O.A. (Oluwole Adegbala), S.O.I. and O.B.; Investigation, S.O.I., O.B., O.A. (Oluwole Adegbala), A.M., M.H. and M.K.; Supervision, O.A. (Oyebimpe Adekolujo). All authors have read and agreed to the published version of the manuscript.

Funding: This research received no external funding.

Institutional Review Board Statement: IRB exempted this study from full review because it was determined to be a non-human study.

Informed Consent Statement: Patient consent was waived because the study utilized de-identified publicly available data.

Data Availability Statement: The data utilized in this study can be found online at www.hcups-us. ahrq.gov (accessed on 31 December 2020).

Acknowledgments: The authors also acknowledge the contributions of Babiker Kheiri and Parul Sud of Mclaren Regional Medical Center, Flint US for their invaluable contributions towards this project. We also acknowledge Muminat Adeniran-Isa for her relentless and critical review of this manuscript.

Conflicts of Interest: The authors declare no conflict of interest.

\section{References}

1. Kapur, V.K.; Auckley, D.H.; Chowdhuri, S.; Kuhlmann, D.C.; Mehra, R.; Ramar, K.; Harrod, C.G. Clinical Practice Guideline for Diagnostic Testing for Adult Obstructive Sleep Apnea: An American Academy of Sleep Medicine Clinical Practice Guideline. J. Clin. Sleep Med. 2017, 13, 479-504. Available online: https://www.ncbi.nlm.nih.gov/pubmed/28162150 (accessed on 9 January 2019). [CrossRef]

2. Cadby, G.; McArdle, N.; Briffa, T.; Hillman, D.R.; Simpson, L.; Knuiman, M.; Hung, J. Severity of OSA is an independent predictor of incident atrial fibrillation hospitalization in a large sleep-clinic cohort. Chest 2015, 148, 945-952. [CrossRef]

3. Young, T.; Palta, M.; Dempsey, J.; Peppard, P.E.; Nieto, F.J.; Hla, K.M. Burden of Sleep Apnea: Rationale, Design, and Major Findings of the Wisconsin Sleep Cohort Study. WMJ Off. Publ. State Med. Soc. Wisconsin 2010, 108, 246-249.

4. Bradley, T.D.; Floras, J.S. Obstructive sleep apnoea and its cardiovascular consequences. Lancet 2009, 373, 82-93. [CrossRef]

5. Fan, J.; Wang, X.; Ma, X.; Somers, V.K.; Nie, S.; Wei, Y. Association of Obstructive Sleep Apnea with Cardiovascular Outcomes in Patients with Acute Coronary Syndrome. J. Am. Heart Assoc. 2019, 8, e010826. [CrossRef] [PubMed] 
6. Correia, L.C.L.; Souza, A.C.; Garcia, G.; Sabino, M.; Brito, M.; Maraux, M.; Rabelo, M.M.N.; Esteves, J.P. Obstructive sleep apnea affects hospital outcomes of patients with non-ST-elevation acute coronary syndromes. Sleep 2012, 35, 1241-5A. [CrossRef] [PubMed]

7. Mohananey, D.; Villablanca, P.A.; Gupta, T.; Agrawal, S.; Faulx, M.; Menon, V.; Kapadia, S.R.; Griffin, B.P.; Ellis, S.G.; Desai, M.Y. Recognized Obstructive Sleep Apnea is Associated with Improved In-Hospital Outcomes after ST Elevation Myocardial Infarction. J. Am. Heart Assoc. 2017, 6, 6. [CrossRef]

8. Agency for Healthcare Research and Quality. HCUP Nationwide Inpatient Sample (NIS). Healthcare Cost and Utilization Project (HCUP); 2011. Available online: http:/ / www.hcup-us.ahrq.gov/nisoverview.jsp (accessed on 9 March 2019).

9. Khera, R.; Angraal, S.; Couch, T.; Welsh, J.W.; Nallamothu, B.K.; Girotra, S.; Chan, P.S.; Krumholz, H.M. Adherence to Methodological Standards in Research Using the National Inpatient Sample. JAMA 2017, 318, 2011-2018. [CrossRef] [PubMed]

10. Sturmer, T.; Wyss, R.; Glynn, R.J.; Brookhart, M.A. Propensity scores for confounder adjustment when assessing the effects of medical interventions using nonexperimental study designs. J. Intern. Med. 2014, 275, 570-580. [CrossRef]

11. Senaratna, C.V.; Perret, J.L.; Lodge, C.J.; Lowe, A.J.; Campbell, B.E.; Matheson, M.C.; Hamilton, G.S.; Dharmage, S.C. Prevalence of obstructive sleep apnea in the general population: A systematic review. Sleep Med. Rev. 2017, 34, 70-81. [CrossRef] [PubMed]

12. Peppard, P.E.; Young, T.; Barnet, J.H.; Palta, M.; Hagen, E.W.; Hla, K.M. Increased prevalence of sleep-disordered breathing in adults. Am. J. Epidemiol. 2013, 177, 1006-1014. [CrossRef]

13. Bixler, E.O.; Vgontzas, A.N.; Ten Have, T.; Tyson, K.; Kales, A. Effects of age on sleep apnea in men: I. Prevalence and severity. Am. J. Respir. Crit. Care Med. 1998, 157, 144-148. [CrossRef]

14. Hnin, K.; Mukherjee, S.; Antic, N.A.; Catcheside, P.; Chai-Coetzer, C.L.; McEvoy, D.; Vakulin, A. The impact of ethnicity on the prevalence and severity of obstructive sleep apnea. Sleep Med. Rev. 2018, 41, 78-86. [CrossRef] [PubMed]

15. Ancoli-Israel, S.; Klauber, M.R.; Stepnowsky, C.; Estline, E.; Chinn, A.; Fell, R. Sleep-disordered breathing in African-American elderly. Am. J. Respir. Crit. Care Med. 1995, 152 Pt 1, 1946-1949. [CrossRef]

16. Gray, E.L.; McKenzie, D.K.; Eckert, D.J. Obstructive Sleep Apnea without Obesity Is Common and Difficult to Treat: Evidence for a Distinct Pathophysiological Phenotype. J. Clin. Sleep Med. JCSM Off. Publ. Am. Acad. Sleep Med. 2017, 13, 81-88. [CrossRef] [PubMed]

17. Siarnik, P.; Klobucnikova, K.; Mucska, I.; Cerna, K.; Kollar, B.; Turcani, P. Obstructive sleep apnea and dyslipidemia. Vnitr. Lek. 2018, 64, 934-938.

18. Mok, Y.; Tan, C.W.; Wong, H.S.; How, C.H.; Tan, K.L.A.; Hsu, P.P. Obstructive sleep apnoea and Type 2 diabetes mellitus: Are they connected? Singapore Med. J. 2017, 58, 179-183. [CrossRef]

19. Marin, J.M.; Carrizo, S.J.; Vicente, E.; Agusti, A.G.N. Long-term cardiovascular outcomes in men with obstructive sleep apnoeahypopnoea with or without treatment with continuous positive airway pressure: An observational study. Lancet 2005, 365, 1046-1053. [CrossRef]

20. Lee, C.-H.; Khoo, S.-M.; Chan, M.Y.; Wong, H.-B.; Low, A.F.; Phua, Q.-H.; Richards, A.M.; Tan, H.-C.; Yeo, T.-C. Severe obstructive sleep apnea and outcomes following myocardial infarction. J. Clin. Sleep Med. JCSM Off. Publ. Am. Acad. Sleep Med. 2011, 7, 616-621. [CrossRef] [PubMed]

21. Arzt, M.; Hetzenecker, A.; Steiner, S.; Buchner, S. Sleep-Disordered Breathing and Coronary Artery Disease. Can. J. Cardiol. 2015, 31, 909-917. [CrossRef]

22. Jia, S.; Zhou, Y.-J.; Yu, Y.; Wu, S.-J.; Sun, Y.; Wang, Z.-J.; Liu, X.-L.; King, B.E.; Zhao, Y.-X.; Shi, D.-M.; et al. Obstructive sleep apnea is associated with severity and long-term prognosis of acute coronary syndrome. J. Geriatr. Cardiol. 2018, 15, 146-152. [CrossRef]

23. Steiner, S.; Schueller, P.O.; Schulze, V.; Strauer, B.E. Occurrence of coronary collateral vessels in patients with sleep apnea and total coronary occlusion. Chest 2010, 137, 516-520. [CrossRef]

24. Joyeux-Faure, M.; Stanke-Labesque, F.; Lefebvre, B.; Beguin, P.; Godin-Ribuot, D.; Ribuot, C.; Launois, S.H.; Bessard, G.; Levy, P. Chronic intermittent hypoxia increases infarction in the isolated rat heart. J. Appl. Physiol. 2005, 98, 1691-1696. [CrossRef]

25. Billah, M.; Ridiandries, A.; Rayner, B.S.; Allahwala, U.K.; Dona, A.; Khachigian, L.M.; Bhindi, R. Egr-1 functions as a master switch regulator of remote ischemic preconditioning-induced cardioprotection. Basic Res. Cardiol. 2019, 115, 3. [CrossRef] [PubMed]

26. Hu, X.; Yang, Z.; Yang, M.; Qian, J.; Cahoon, J.; Xu, J.; Sun, S.; Tang, W. Remote ischemic preconditioning mitigates myocardial and neurological dysfunction via K(ATP) channel activation in a rat model of hemorrhagic shock. Shock 2014, 42, 228-233. [CrossRef] [PubMed]

27. Kim, K.T.; Moon, H.-J.; Yang, J.-G.; Sohn, S.-I.; Hong, J.-H.; Cho, Y.W. The prevalence and clinical significance of sleep disorders in acute ischemic stroke patients-a questionnaire study. Sleep Breath. 2017, 21, 759-765. [CrossRef] [PubMed]

28. Curtis, J.P.; Selter, J.G.; Wang, Y.; Rathore, S.S.; Jovin, I.S.; Jadbabaie, F.; Kosiborod, M.; Portnay, E.L.; Sokol, S.I.; Bader, F.; et al. The obesity paradox: Body mass index and outcomes in patients with heart failure. Arch. Intern. Med. 2005, 165, 55-61. [CrossRef]

29. Lechi, A. The obesity paradox: Is it really a paradox? Hypertension. Eat. Weight Disord. 2017, 22, 43-48. [CrossRef] 